\title{
Severe Acute Respiratory Syndrome
}

National Cancer Institute

\section{Source}

National Cancer Institute. Severe Acute Respiratory Syndrome. NCI Thesaurus. Code C85064.

A viral respiratory infection caused by the SARS coronavirus. It is transmitted through close person-to-person contact. It is manifested with high fever, headache, dry cough and myalgias. It may progress to pneumonia and cause death. 